\title{
CORRELATION BETWEEN MYOCARDIAL PERFUSION IMAGING AND CAROTID ULTRA- SONOGRAPHY IN PATIENTS WITH CHEST PAIN
}

\author{
By
}

\author{
Ahmed Abd El-Aziz Hassan Abd El-Aziz, Abd El-Halim Mohammed \\ Abo El-Magd, Ayman El-Saeid Sadek and Mohamed Talaat Mohamed* \\ Departments of Cardiology and Radiology*, Faculty of Medicine, Al-Azhar University \\ Corresponding author: Ahmed Abd El-Aziz Hassan Abd El-Aziz, \\ E-mail: ahmedabdelaziz1516@yahoo.com
}

\begin{abstract}
Background: Atherosclerosis is a major risk factor for coronary artery disease (CAD). Carotid ultrasound (U/S) may be a useful method for prediction of CAD through measurement of intimio-media thickness (IMT) of right and left common carotic arteries.

Objective: To emphasize the correlation between myocardial perfusion imaging using single photon emission computed tomography (SPECT) and carotid ultrasound through measuring IMT in early prediction and diagnosis of CAD.

Patients and methods: The study included 80 patients complaining from chest pain. Single photon emission computed tomography (SPECT) and carotid U/S were done to each of them. All Patients were recruited from El-Hussein university hospital outpatient clinic and Kobry El-Koba military hospital outpatient clinic between February 2020 and November 2020.

Results: The study included 80 patients, 57 of them were males while 23 of them were females. 52 patients were hypertension (HTN), 31 patients were diabetes mellitus (DM), 33 patients were smokers, 15 patients of them had positive family history. 52 patients had positive SPECT stress test revealing CAD "ischemic group", while 28 of them had negative SPECT stress test "Non-ischemic group". For the ischemic group, 43 patients $(82.7 \%)$ had increased intimio-media thickness IMT. Right IMT mean \pm SD " $0.69 \pm 0.10$ ", t-test "7.771", weighted Kappa test 0.655 substantial agreement and P-value "p $<0.001$ ". Lefy IMT mean \pm SD “ $0.77 \pm 0.12$ ", t-test " 5.122 ", weighted Kappa test 0.614 substantial agreement and p-value "p $<0.001$ ". Only 9 patients (17.3\%) from the ischemic group had below 75th percentile IMT. For Non-ischemic group, only 9 patients $(32.1 \%)$ had abnormal IMT while the other 19 patients (67.9\%) had normal IMT.
\end{abstract}

Conclusion: Carotid ultrasound and intimio-media thickness are good predictors and highly correlated to coronary artery disease.

Keywords: SPECT, Carotid U/S, Intimio-media thickness, CAD.

\section{INTRODUCTION}

The worldwide health burden has shifted from communicable, maternal and perinatal causes to non-communicable diseases with cardiovascular diseases (CVDs) being the largest single contributor worldwide. CAD is the most common and hazardous cardiovascular disease. Its incidence and the resultant morbidity and mortality increase every year, especially in the elderly (Rusnak et al., 2017).

Coronary atherosclerosis can lead to different graded stenosis of coronary 
arteries causing decreased blood flow to the myocardium and dysfunction of the affected myocardial segments. Early detection and intervention whether medically or invasively are of utmost value to preserve left ventricular (LV) systolic functions (McPherson and Tybjaerg-Hansen, 2016).

Noninvasive identification of patients with CAD remains a clinical challenge despite the widespread use of imaging and provocative testing; more than $50 \%$ of patients currently referred to coronary angiography show normal or nonobstructive CAD (Ruigómez et al., 2010).

Myocardial perfusion imaging (MPI) is a non-invasive imaging test that shows how well blood flows through (perfuses) your heart muscle. It can show areas of the heart muscle that aren't getting enough blood flow. This test is often called a nuclear stress test. It can also show how well the heart muscle is pumping. There are 2 techniques for MPI: single photon emission computed tomography (SPECT) and positron emission tomography (PET). MPI is useful in patients with chest discomfort to see if the discomfort comes from lack of blood flow to the heart muscle caused by narrowed or blocked heart arteries (angina). Myocardial perfusion imaging doesn't show the heart arteries themselves, but can tell your doctor with good certainty if any heart arteries are blocked and how many. MPI can also show if you've previously had a heart attack. A radioactive tracer (called Myoview) is injected into the patient's bloodstream and is taken up by the heart tissue. A single photon emission computed tomography (SPECT) camera detects the radiation released by the tracer to produce images of the heart. Two sets of images are taken, one after an injection at rest and another after an injection during a stress test - either exercise stress on a treadmill or drug-induced stress with persantine (dipyridamole) medication, which simulates exercise (Fihn et al., 2012).

Intima-media thickness (IMT), also called intimal medial thickness, is a measurement of the thickness of tunica intima and tunica media, the innermost two layers of the wall of an artery. The measurement is usually made by external ultrasound and occasionally by internal, invasive ultrasound catheters. Measurements of the total wall thickness of blood vessels can also be done using other imaging modalities (Go et al., 2013).

The carotid artery is the usual site of measurement of IMT and consensus statements for carotid IMT have been published for adults and children. Often, IMT is measured in three locations: in the common carotid artery (typically at one $\mathrm{cm}$ proximal to the flow divider), at the bifurcation, and in the internal carotid artery. IMT measurements of the far (deeper) wall, by ultrasound, are generally considered more reliable than measurements performed on the near (more superficial) wall; although measurement of both near and far wall IMT has also been advocated (Staub, 2018).

The aim of this study was to identify the correlation between myocardial perfusion imaging using SPECT., and measuring carotid ultra-sonography as 
predictors of presence of coronary artery disease in patients with chest pain.

\section{PATIENTS AND METHODS}

This study included 80 patients of both genders "males and females" complaining from chest pain. The included cases were recruited from the Outpatient clinic and Inpatients at El-Hussein univesity hospital and Kobry El Kobba Military Hospital between February 2020 and November 2020.

Inclusion criteria: Adult patients between 18-80 years of age with chest pain.

\section{Exclusion criteria:}

Any patient with:

1. Multi-valvular Lesions.

2. Severe malignant arrhythmia.

3. End organ damage "Renal failure, Liver failure, Metastatic cancer"

4. Any contraindication to exercise test.

5. Any contraindication to MPI test.

\section{All patients were subjected to:}

History and physical examination: Upon enrollment all patients were have a review of their medical history, including demographic data (age, gender, body mass index $[\mathrm{BMI}])$, and presence of risk factors for coronary atherosclerosis (smoking, diabetes, hypertension, dyslipidemia, family history of premature CAD) and associated co-morbidities.

\section{Clinical examination:}

Vital signs: e.g.: heart rate, blood pressure. Signs of heart failure or hemodynamic instability. Local cardiac examination.

Twelve-lead ECG: 12 leads surface electrocardiography to exclude any arrhythmia or the presence of Q waves or ST-T wave changes at rest.

Laboratory investigation: Lipid profile (LDL- HDL - TGDs - Cholesterol), kidney function tests.

\section{Transthoracic Echocardiography analysis:}

All echocardiographic examinations were performed after $20-30 \mathrm{~min}$ of rest with the patient in quiet respiration in the partial left lateral decubitus position, using a 2-4 $\mathrm{MHz}$ transducer, and was accompanied by recording resting electrocardiography. All measurements were obtained online and echocardiographic parameters were measured according to the American Society of Echocardiography Values. For each parameter was obtained by averaging measurements from three successive cardiac cycles. Left ventricularenddiastolic and end-systolic diameters was measured and LV ejection fraction (EF) was calculated by Simpson's rule.

Carotid arteries U/S Doppler study: All patients were have carotid U/S Doppler study with measuring carotid intimamedia thickness at the nearest wall and stratified into two groups according to European society of cardiography guidelines. 


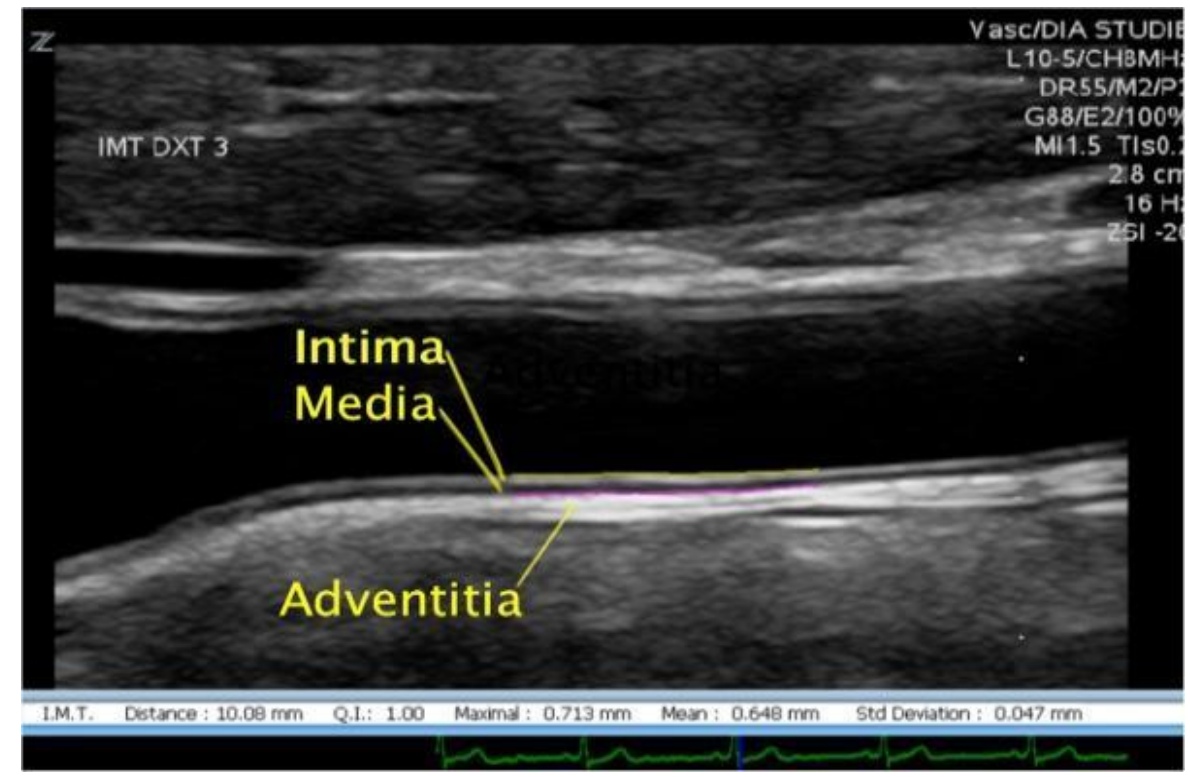

Figure (1): Carotid U/S measuring Intima media thickness.

Myocardial perfusion study using SPECT:

The study was done at "two-day" protocol. In the first day all patients undergo exercise stress on treadmill according to Bruce protocol. Then patients were injected with radioactive tracer and subjected to gamma camera for the stress film. The next day patients were subjected to gamma camera for the rest film and then the 2 films were analyzed by SPECT analysis system.

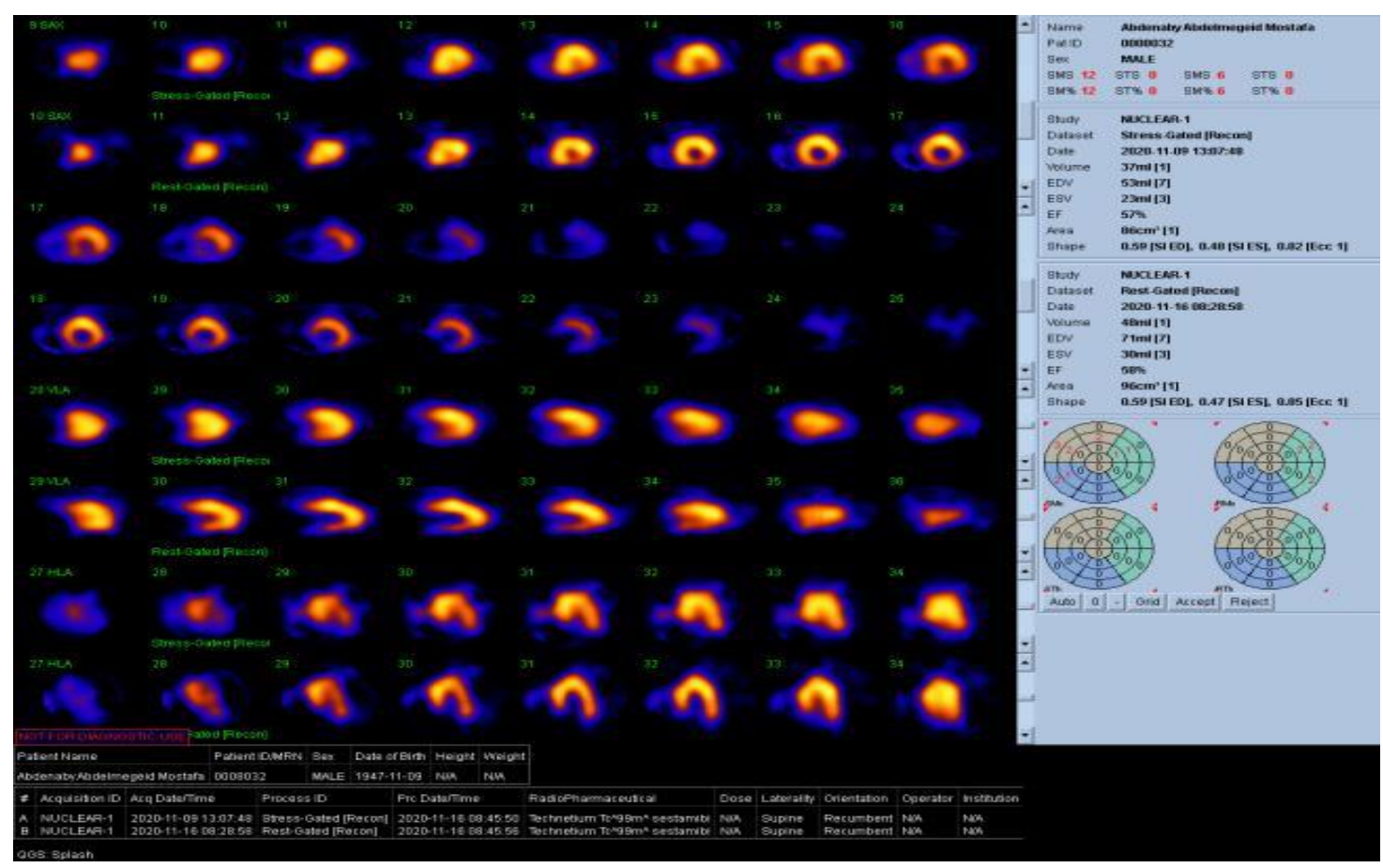

Figure (2): Real patient SPECT stress/rest film after analysis. 
For each patient LV EF was calculated and ischemic areas either reversible or scared tissues was detected.

\section{Statistical Analysis:}

Recorded data were analyzed using the statistical package for social sciences, version 20.0 (SPSS Inc., Chicago, Illinois, USA). Quantitative data were expressed as mean \pm standard deviation (SD). Qualitative data were expressed as frequency and percentage. Independentsamples t-test of significance was used when comparing between two means. Chi- square (x2) test of significance was used in order to compare proportions between qualitative parameters. Kappa measure of agreement between Technicium scan and Carotid duplex, a value of: $0-0.20$ indicates slight agreement; $0.21-0.40$, fair agreement; $0.41-\quad 0.60$, moderate agreement; $0.61-\quad 0.80$, substantial agreement; and 0.81-1.00, almost perfect agreement. The confidence interval was set to $95 \%$ and the margin of error accepted was set to $5 \%$. So,

\section{RESULTS}

This was a prospective study conducted on 80 patients to demonstrate the correlation between ischemic heart disease and atherosclerotic changes at carotid arteries.

The mean age of the patients was 57.50 \pm 8.77 years (range 39-76years). There were $23(28.8 \%)$ female and 57 $(71.3 \%)$ male of demographic data.
This table shows that there were HTN 52 (65.0\%), DM 31 (38.8\%), Smoking 33 (41.3\%), CA or PCI PCI 15 (18.8\%), CA 5 (6.3\%), CABG 2 (2.5\%), PCI LAD 1 (1.3\%), PCI, CABG 1 (1.3\%), Post covid 1 (1.3\%), Family Hx 15 (18.8\%), Urea $38.28 \pm 12.05$ and Creat $1.12 \pm 0.50$ of history \& Laboratory data (Table 1). 
Table (1): Distribution of patients with chest pain according to their demographic data regarding gender, age, HTN, DM, CA or PCI, family history, urea and creat $(n=80)$. $(n=80)$

\begin{tabular}{|c|c|}
\hline Demographic data & Total $(\mathrm{n}=80)$ \\
\hline Gender & $\mathbf{2 3}(\mathbf{2 8 . 8 \%})$ \\
\hline Female & $\mathbf{5 7}(\mathbf{7 1 . 3 \%})$ \\
\hline Male & $\mathbf{3 9 - 7 6}$ \\
\hline Age (years) & $\mathbf{5 7 . 5 0} \pm \mathbf{8 . 7 7}$ \\
\hline Range & $\mathbf{5 2}(\mathbf{6 5 . 0 \%})$ \\
\hline Mean \pm SD & $\mathbf{3 1}(\mathbf{3 8 . 8 \%})$ \\
\hline HTN & $\mathbf{3 3}(\mathbf{4 1 . 3 \%})$ \\
\hline DM & \\
\hline Smoking & $\mathbf{5 ( 6 . 3 \% )}$ \\
\hline CA or PCI & $\mathbf{2}(\mathbf{2 . 5 \%})$ \\
\hline CA & $\mathbf{5 5}(\mathbf{6 8 . 8 \%})$ \\
\hline CABG & $\mathbf{1 7}(\mathbf{2 1 . 2 \%})$ \\
\hline No & $\mathbf{1}(\mathbf{1 . 3 \%})$ \\
\hline PCI & $\mathbf{1 5}(\mathbf{1 8 . 8 \%})$ \\
\hline Post covid & $\mathbf{2 6 - 1 1 2}[38.28 \pm \mathbf{1 2 . 0 5}]$ \\
\hline Family Hx & $\mathbf{0 . 6}-4.2[1.12 \pm 0.50]$ \\
\hline Urea &
\end{tabular}

Ischemic and Non-Ischemic patients:

Comparison between Ischemic and non-ischemic patients "by SPECT results" according to demographic data, history, lab \& Echo results.

This table shows statistically significant higher male in Ischemic group $(80.8 \%)$ compared to non-Ischemic group $(53.6 \%)$, with p-value <0.05 S; while age (years) insignificant difference. This table shows statistically significant higher smoker in Ischemic group (50\%) compared to non-Ischemic group (25\%), with p-value <0.05 S; while HTN, DM,
CA or PCI, family, urea and creat. insignificant difference.

This table shows statistically significant increase mean in Ischemic group compared to non-Ischemic according to TGDs and LDL, while HDL significant decrease mean in Ischemic group compared to non-Ischemic group.

This table shows highly statistically significant higher SWMA in Ischemic group $(80.8 \%)$ compared to non-Ischemic group (10.7\%), with p-value <0.001 HS; while EF\% significant decrease mean in Ischemic group compared to non-Ischemic group (Table 2). 
Table (2): Comparison between Ischemic and non-Ischemic according to demographic data, history \& Lab data, lipid profile and echo

\begin{tabular}{|c|c|c|c|}
\hline Demographic data & $\begin{array}{c}\text { Ischemic } \\
(\mathrm{n}=52)\end{array}$ & $\begin{array}{c}\text { Non-Ischemic } \\
(\mathrm{n}=28)\end{array}$ & p-value \\
\hline Gender & & & \\
\hline Female & $10(19.2 \%)$ & $13(46.4 \%)$ & \multirow{2}{*}{$0.010 *$} \\
\hline Male & $42(80.8 \%)$ & $15(53.6 \%)$ & \\
\hline \multicolumn{4}{|l|}{ Age (years) } \\
\hline Mean \pm SD & $56.65 \pm 9.00$ & $59.07 \pm 8.25$ & \multirow{2}{*}{0.242} \\
\hline Range & $39-76$ & 43-76 & \\
\hline \multicolumn{4}{|l|}{ History \& Lab data } \\
\hline \multicolumn{4}{|l|}{ HTN } \\
\hline No & $20(38.5 \%)$ & $8(28.6 \%)$ & \multirow{2}{*}{0.376} \\
\hline Yes & $32(61.5 \%)$ & $20(71.4 \%)$ & \\
\hline \multicolumn{4}{|l|}{ DM } \\
\hline No & $30(57.7 \%)$ & $19(67.9 \%)$ & \multirow{2}{*}{0.373} \\
\hline Yes & $22(42.3 \%)$ & $9(32.1 \%)$ & \\
\hline \multicolumn{4}{|l|}{ Smoking } \\
\hline No & $26(50.0 \%)$ & $21(75.0 \%)$ & \multirow{2}{*}{$0.029 *$} \\
\hline Yes & $26(50.0 \%)$ & $7(25.0 \%)$ & \\
\hline \multicolumn{4}{|l|}{ CA or PCI } \\
\hline CA & $4(7.7 \%)$ & $1(3.6 \%)$ & \multirow{6}{*}{0.235} \\
\hline CABG & $3(5.8 \%)$ & $0(0.0 \%)$ & \\
\hline PCI & $12(23.1 \%)$ & $4(14.3 \%)$ & \\
\hline PCI LAD & $0(0.0 \%)$ & $1(3.6 \%)$ & \\
\hline Post covid & $0(0.0 \%)$ & $1(3.6 \%)$ & \\
\hline No & $34(65.4 \%)$ & $21(75.0 \%)$ & \\
\hline \multicolumn{4}{|l|}{ Family Hx } \\
\hline No & $40(76.9 \%)$ & $25(89.3 \%)$ & \multirow{2}{*}{0.177} \\
\hline Yes & $12(23.1 \%)$ & $3(10.7 \%)$ & \\
\hline \multicolumn{4}{|l|}{ Urea } \\
\hline Mean \pm SD & $39.71 \pm 14.12$ & $35.61 \pm 6.12$ & \multirow{2}{*}{0.147} \\
\hline Range & 26-112 & $26-54$ & \\
\hline \multicolumn{4}{|l|}{ Creat } \\
\hline Mean \pm SD & $1.18 \pm 0.59$ & $1.02 \pm 0.21$ & \multirow{2}{*}{0.166} \\
\hline Range & $0.6-4.2$ & $0.7-1.4$ & \\
\hline
\end{tabular}

\begin{tabular}{|c|c|c|c|}
\hline Lipid profile & & & \\
\hline Cholesterol & & & \multirow{3}{*}{0.115} \\
\hline Mean \pm SD & $216.90 \pm 42.71$ & $201.75 \pm 36.09$ & \\
\hline Range & 113-301 & 154-275 & \\
\hline TGDs & & & \multirow{3}{*}{$0.013 *$} \\
\hline Mean \pm SD & $240.12 \pm 56.21$ & $209.36 \pm 42.18$ & \\
\hline Range & 124-376 & 134-289 & \\
\hline LDL & & & \multirow{3}{*}{$0.026^{*}$} \\
\hline Mean \pm SD & $117.75 \pm 19.49$ & $107.68 \pm 17.66$ & \\
\hline Range & $77-154$ & $73-145$ & \\
\hline HDL & & & \\
\hline Mean \pm SD & $34.62 \pm 4.99$ & $36.89 \pm 5.27$ & \multirow{2}{*}{$0.041 *$} \\
\hline Range & $26-45$ & $26-47$ & \\
\hline Echo & & & \\
\hline SWMA & & & \\
\hline No & $10(19.2 \%)$ & $25(89.3 \%)$ & \multirow{2}{*}{$<0.001 * *$} \\
\hline Yes & $42(80.8 \%)$ & $3(10.7 \%)$ & \\
\hline $\mathrm{EF} \%$ & & & \\
\hline Mean \pm SD & $48.29 \pm 13.22$ & $63.07 \pm 5.79$ & \multirow{2}{*}{$<0.001 * *$} \\
\hline Range & $25-73$ & 51-75 & \\
\hline
\end{tabular}


Comparison between Ischemic and nonischemic patients according to results of Carotid U/S:

This table shows highly statistically significant higher mean in Ischemic group compared to non-Ischemic group according to carotid duplex regarding RT IMT and Lt IMT. This table shows highly statistically significant higher in Ischemic group $(82.7 \%)$ compared to non-Ischemic group $(32.1 \%)$ according to RT IMT normality, weighted Kappa test 0.655 substantial agreement, while LT IMT normality in Ischemic group $(82.7 \%)$ compared to non-Ischemic group (35.7\%), weighted Kappa test 0.614 substantial agreement, about carotid duplex. This table shows statistically significant higher in Ischemic group (21.2\%) compared to non-Ischemic group (3.6\%) according to presence of atherosclerotic plaque (Table 3).

Table (3): Comparison between Ischemic and non-Ischemic groups according to carotid U/S results regarding RT IMT, Lt IMT, RT IMT normality, LT IMT normality and presence of a plaque

\begin{tabular}{|c|c|c|c|}
\hline Carotid duplex & $\begin{array}{c}\text { Ischemic } \\
(n=52)\end{array}$ & $\begin{array}{c}\text { Non-Ischemic } \\
(\mathrm{n}=28)\end{array}$ & p-value \\
\hline \multicolumn{4}{|l|}{ RT IMT } \\
\hline Mean \pm SD & $0.69 \pm 0.10$ & $0.58 \pm 0.06$ & \multirow{2}{*}{$<0.001 * *$} \\
\hline Range & $0.5-1.1$ & $0.5-0.7$ & \\
\hline \multicolumn{4}{|l|}{ Normal RT } \\
\hline Mean \pm SD & $0.60 \pm 0.04$ & $0.60 \pm 0.02$ & \multirow{2}{*}{0.799} \\
\hline Range & $0.5-0.62$ & $0.53-0.62$ & \\
\hline \multicolumn{4}{|l|}{ Lt IMT } \\
\hline Mean \pm SD & $0.77 \pm 0.12$ & $0.66 \pm 0.09$ & \multirow{2}{*}{$<0.001 * *$} \\
\hline Range & $0.56-1.1$ & $0.5-0.9$ & \\
\hline \multicolumn{4}{|l|}{ Normal Lt } \\
\hline Mean \pm SD & $0.67 \pm 0.05$ & $0.61 \pm 0.25$ & \multirow{2}{*}{0.134} \\
\hline Range & $0.57-0.7$ & $-0.64-0.7$ & \\
\hline \multicolumn{4}{|l|}{ Carotid duplex } \\
\hline \multicolumn{4}{|l|}{ RT IMT normality } \\
\hline Abnormal & $43(82.7 \%)$ & $9(32.1 \%)$ & \multirow{2}{*}{$<0.001 * *$} \\
\hline Normal & $9(17.3 \%)$ & $19(67.9 \%)$ & \\
\hline \multicolumn{4}{|l|}{ LT IMT normality } \\
\hline Abnormal & $43(82.7 \%)$ & $10(35.7 \%)$ & \multirow{2}{*}{$<0.001 *$} \\
\hline Normal & $9(17.3 \%)$ & $18(64.3 \%)$ & \\
\hline \multicolumn{4}{|l|}{ Presence of a plaque } \\
\hline $\begin{array}{l}\text { No } \\
\text { Yes }\end{array}$ & $\begin{array}{l}41(78.8 \%) \\
11(21.2 \%)\end{array}$ & $\begin{array}{c}27(96.4 \%) \\
1(3.6 \%)\end{array}$ & $0.036^{*}$ \\
\hline
\end{tabular}

\section{DISCUSSION}

This was a prospective study conducted on 80 subjects of both genders "males and females" complaining from chest pain. The included cases were recruited from the outpatient clinic and inpatients at El Hussein univesity hospital and Kobry El Kobba military hospital between february 2020 and november 2020.

Many studies evaluated the role of carotid U/S in detection of arterial 
atherosclerosis through measuring of intima media thickness and detection of any atheromatous plaques at carotid arteries; however a limited number of researchers in literature were discussing the correlation between stress cardiac imaging \& viability tests and carotid U/S.

So, we aimed in this study to emphasize on the role of carotid U/S in early detection of ongoing atherosclerotic process and its correlation to diagnosis of coronary artery disease through myocardial perfusion imaging through SPECT.

There was a statistically significant higher number of males with positive stress imaging through SPECT "Ischemic group" (80.8\%) compared to negative stress imaging "non-Ischemic group" $(53.6 \%)$, with "p-value $<0.0$ ".

There was statistically significant higher number of smokers in Ischemic group (50\%) compared to non-Ischemic group $(25 \%)$, with "p-value $<0.05$ ".

Increased IMT was considered abnormal if more than "75th percentile per age and sex" of right and left carotid IMT by Yano et al. (2016).

There was statistically significant higher mean IMT in the "ischemic group" than mean IMT in the "non-ischemic group".

For Ischemic group, right IMT range was 0.5-1.1 with Mean \pm SD 0.69 \pm 0.10 while normal 75 th percentile range was 0.5-0.62 with Mean \pm SD 0.60 \pm 0.04 .

For Ischemic group, left IMT range was 0.56-1.1 with Mean \pm SD $0.77 \pm 0.12$ while normal 75 th percentile range was $0.57-0.7$ with Mean \pm SD $0.67 \pm 0.05$.
For Non-ischemic group, right IMT range was $0.5-0.7$ with Mean \pm SD $0.58 \pm 0.06$ while normal 75 th percentile range was $0.5-0.62$ with Mean \pm SD $0.60 \pm 0.04$.

For Non-ischemic group, left IMT range was 0.5-0.9 with Mean \pm SD $0.66 \pm 0.09$ while normal 75 th percentile range was $0.64-0.7$ with Mean \pm SD $0.61 \pm 0.25$.

There was 43 patients with increased IMT out of 52 patients in the "ischemic group" with percentage $82.6 \%$ with (Pvalue $<0.001 * *$ ) weighted Kappa test 0.614 substantial agreement.

There were only 9 patients with increased IMT out of 28 patients in the "non-ischemic group" with percentage $32.1 \%$.

This agreed with Mitevska et al. (2017) who had 60 asymptomatic DMT2 patients (pts) without known coronary artery disease (CAD) underwent one day rest Dypiridamole stress Tc-99m sestamibi single photon emission computed tomography myocardial perfusion imaging (MPI). 18 (31\%) patients had myocardial ischemia. Mild ischemia was found in 6 pts, moderate in 7 patients and severe ischemia in 5 patients. Carotid IMT was increased in 34 pts and 15 pts had carotid plaques. Mean c-IMT value in patients with normal MPS results was 0.7 \pm 0.1 ; in moderate ischemia $0.9 \pm 0.1$ and in pts severe ischemia $1.0 \pm 0.2$.

This also agreed with Djaberi et al. (2010) who found that Increased CIMT was significantly related to the presence and extent of abnormal myocardial perfusion. Assessment of CIMT may be useful to identify asymptomatic patients 
with type 2 diabetes at higher risk for CAD.

Overall, 34 patients (35\%) showed abnormal perfusion (SSS $\geq 3$ ), including severely abnormal perfusion (SSS $\geq 8$ ) in 14 patients (14\%). Average CIMT was $0.68 \pm 0.12 \mathrm{~mm}$. Comparison with reference values revealed normal CIMT in 60 patients $(61 \%)$, while in the remaining 38 patients $(39 \%)$ an increased CIMT value was observed in at least one CCA. Abnormal perfusion was present in 9\% of patients with normal CIMT versus $75 \%$ of patients with increased CIMT. Notably, prevalence of severely abnormal perfusion increased from $3 \%$ in patients with normal CIMT to $28 \%$ in those with increased CIMT with $\mathrm{P}$ value $(\mathrm{P}<0.001)$.

It also agreed with Boucher et al. (2010) who conducted repeated Doppler measurements of the CIT of primitive carotid arteries in 52 diabetic patients aged 49 to 75 . All these asymptomatic patients, without coronary antecedents, diabetic for more than 10 years and exhibiting at least one cardiovascular risk factor, had undergone myocardial scintigraphy.

$\mathrm{He}$ found that CIMT was greater in the group with positive scintigraphies and is the best predictive factor of the presence of ischemia. For a CIT value $<0.55 \mathrm{~mm}$, the negative predictive value of the CIT was of $77 \%$ with $80 \%$ sensitivity; in nonsmokers the predictive negative value increased to $92 \%$ with $95 \%$ sensitivity.

\section{CONCLUSION}

Myocardial perfusion imaging through SPECT is a useful method of diagnosis of CAD. Carotid U/S is a good predictor of atherosclerosis. Carotid Intimio-media thickness is a good predictor and highly correlated to coronary atherosclerosis and CAD.

\section{REFERENCES}

1. Boucher B, Cerisier A, Bouchou $\mathrm{K}$, Brulport-Cerisier V, Charmion S, Estour B and Cathébras, P. (2010): Silent myocardial ischemia in type 2 diabetes. Predictive value of intimamedia thickness. Presse Med., 31(5): 218-222.

2. Djaberi R, Schuijf JD, Jukema JW, Rabelink TJ and Bax JJ. (2010): Increased carotid intima-media thickness as a predictor of the presence and extent of abnormal myocardial perfusion in type 2 diabetes. Diabetes Care, 33(2): 372374.

3. Fihn SD, Gardin JM, Abrams J, Berra K and Williams SV. (2012): 2012

ACCF/AHA/ACP/AATS/PCNA/SCA I/STS Guideline for the diagnosis and management of patients with stable ischemic heart disease: a report of the American College of Cardiology Foundation/American Heart Association Task Force on Practice Guidelines, and the American College of Physicians, American Association for Thoracic Surgery, Preventive Cardiovascular Nurses Association, Society for Cardiovascular Angiography and Interventions, and Society of Thoracic Surgeons. J Am Coll Cardiol., 60(24): 44-164.

4. Go AS, Mozaffarian D, Roger VL, Benjamin EJ, Berry JD Borden WB and Turner MB. (2013): Heart disease and stroke statistics--2013 
update: a report from the American Heart Association. Circulation, 127(1): 6-245.

5. McPherson $R$ and Tybjaerg-Hansen A. (2016): Genetics of Coronary Artery Disease. Circ Res., 118(4): 564-578.

6. Mitevska IP, Baneva N, Bosevski M and Kostovska ES. (2017): Prevalence of risk factors and asymptomatic carotid atherosclerosis in diabetic patients screened for silent myocardial ischemia by SPECT myocardial imaging. Nucl Med Rev Cent East Eur., 20(1): 3-9.

7. Ruigómez A, Rodríguez LA, Wallander MA, Johansson $S$ and Jones R. (2010): Chest pain in general practice: incidence, comorbidity and mortality. Fam Pract., 23(2): 167-174.
8. Rusnak J, Fastner C, Behnes M, Mashayekhi $K$, Borggrefe $M$ and Akin I. (2017): Biomarkers in Stable Coronary Artery Disease. Curr Pharm Biotechnol., 18(6): 456-471.

9. Staub D. (2018): Duplex ultrasound in cerebrovascular disease asymptomatic carotid stenosis. Ther Umsch., 75(8): 489-495.

10. Yano M, Miura S, Shiga Y, Miyase $Y$, Suematsu $Y$, Norimatsu $K$ and Saku K. (2016): Association between smoking habits and severity of coronary stenosis as assessed by coronary computed tomography angiography. Heart Vessels, 31(7): 1061-1068. 


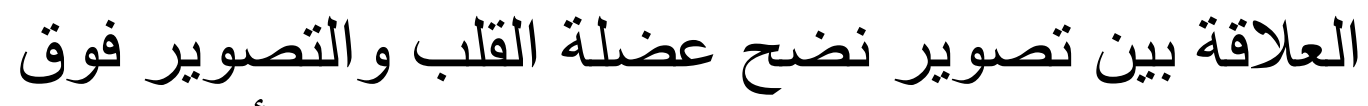

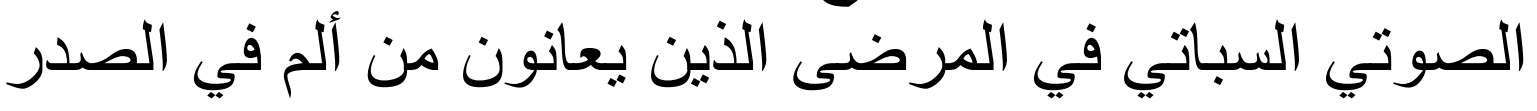

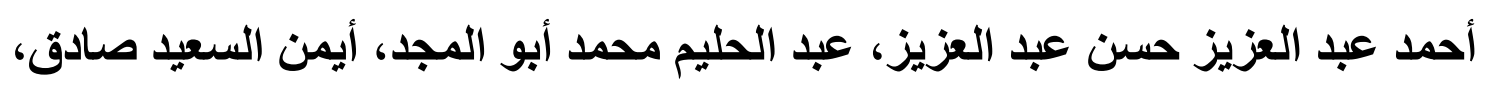
محمد طلعت محمد*

قسمي أمراض القلب و الأشعة *، كلية الطب، جامعة الأزهر

E-mail: $\underline{\text { ahmedabdelaziz1516@yahoo.com }}$

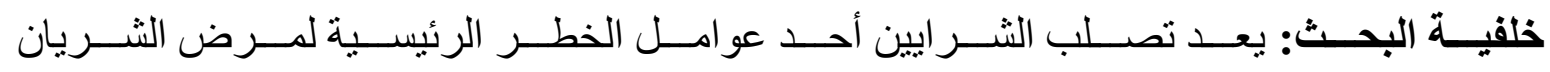

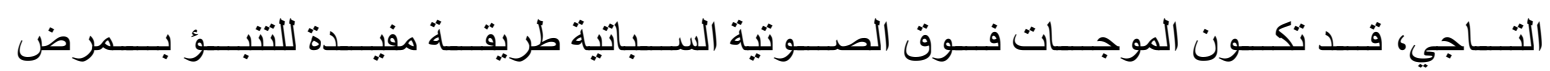

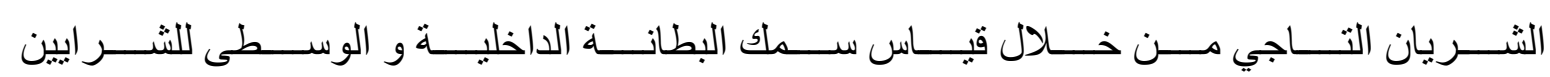

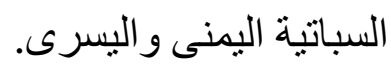

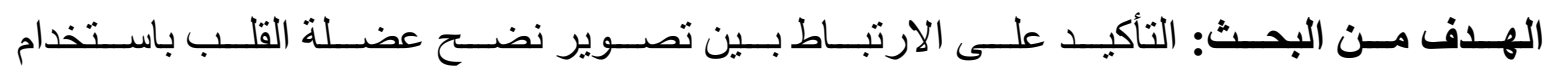

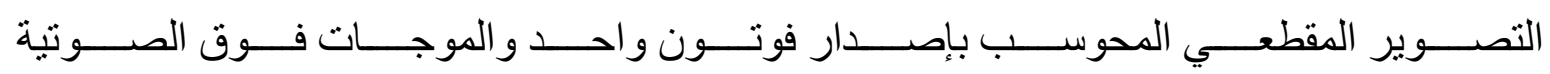

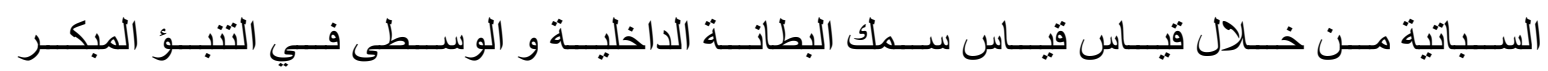
وتشخيص مرض الثريان التاجي.

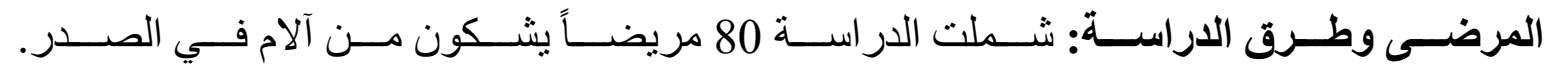

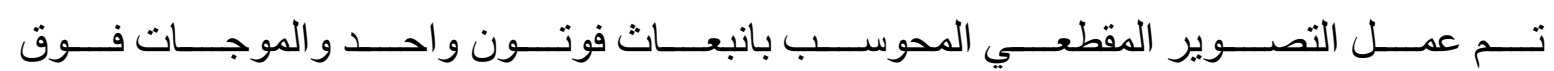

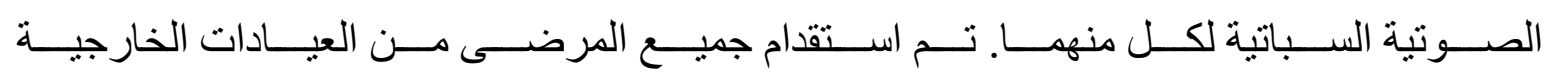

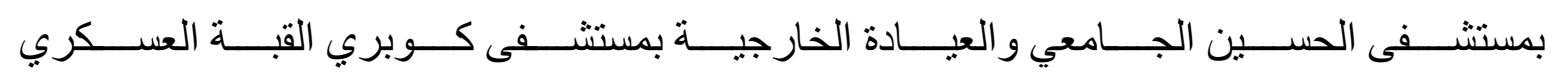
بين فبر اير 2020 ونوفمبر 2020.

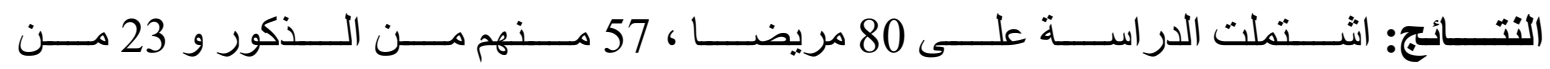

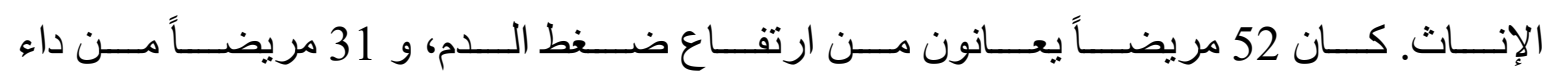

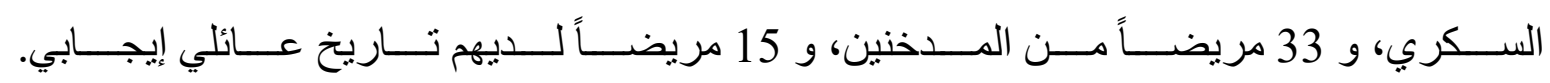

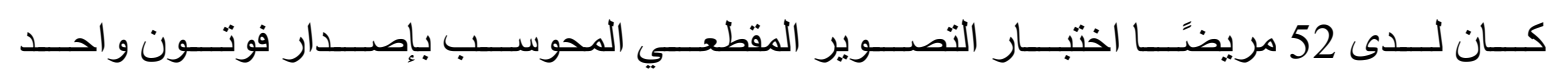

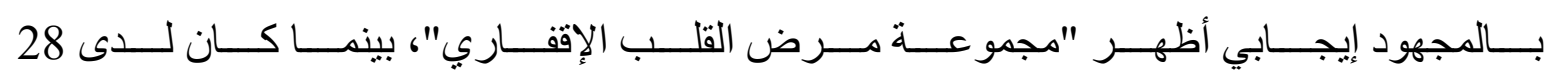

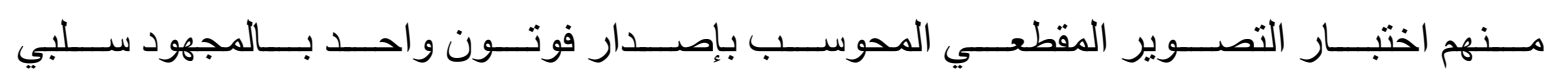

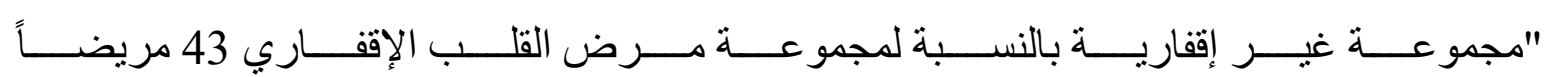




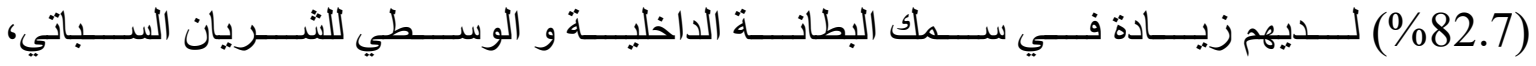

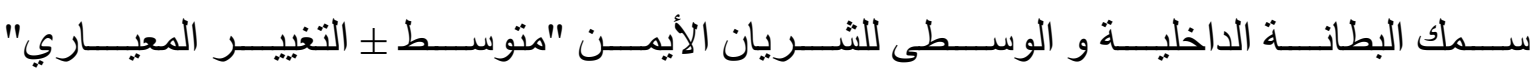

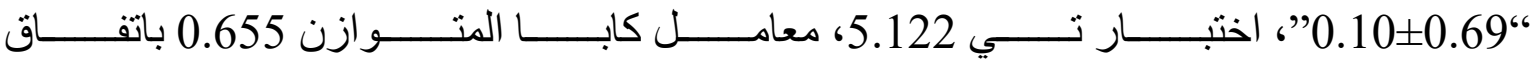
جوهري و قيمة بي >0.001.

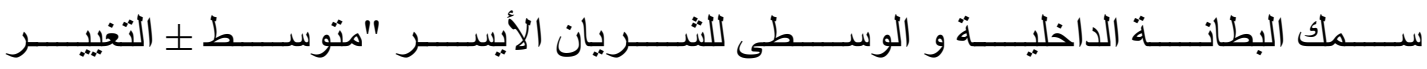

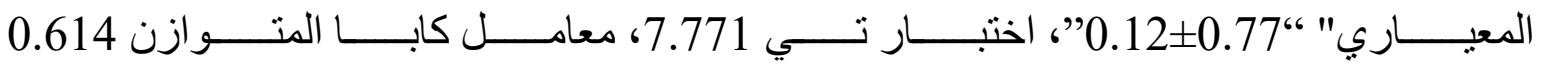
باتفاق جو هري و قيمة بي >0.001.

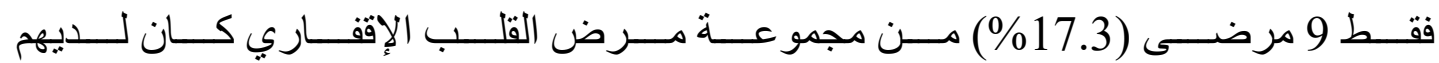
سمك البطانة الداخلية و الوسطى للثريان الثباتي أقل من الثريحة المئوية ال 75.

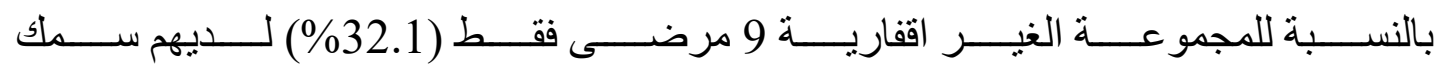

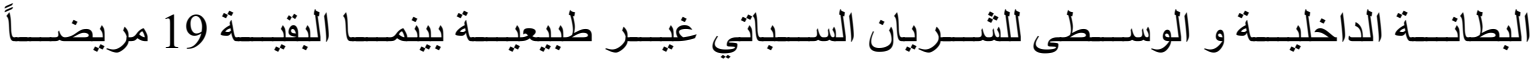
(\%67.1) كان لديهم سمك البطانة طبيعي.

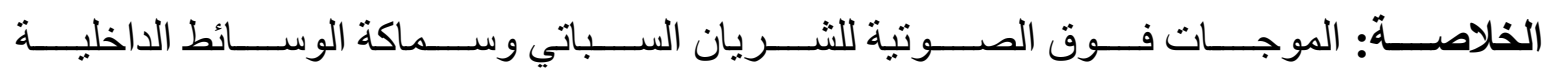
منبئات جيدة ومرتبطة بشكل كبير بمرض الثريان التاجي.

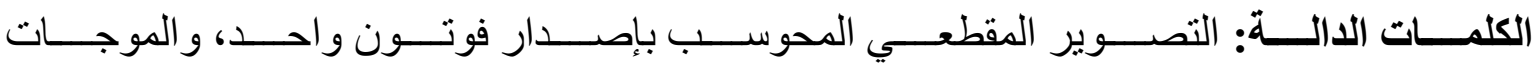
فوق الصوتية السباتية، سماكة الوسائط الداخلية، لمرض الثريان التاجي. 